\title{
Dynamic Test Bed Analysis of Gas Energy Balance for a Diesel Exhaust System Fit with a Thermoelectric Generator
}

\author{
PAWEL FUC, ${ }^{1}$ PIOTR LIJEWSKI, ${ }^{1}$ ANDRZEJ ZIOLKOWSKI, ${ }^{1,2}$ \\ and MICHAL DOBRZYŃSKI ${ }^{1}$ \\ 1.-Faculty of Machines and Transport, Institute of Combustion Engines and Transport, Poznan \\ University of Technology Poland, ul Piotrowo 3, 60-965 Poznan, Poland. 2.-e-mail: \\ andrzej.j.ziolkowski@put.poznan.pl
}

\begin{abstract}
Analysis of the energy balance for an exhaust system of a diesel engine fit with an automotive thermoelectric generator (ATEG) of our own design has been carried out. A special measurement system and dedicated software were developed to measure the power generated by the modules. The research object was a 1.3-l small diesel engine with power output of $66 \mathrm{~kW}$. The tests were carried out on a dynamic engine test bed that allows reproduction of an actual driving cycle expressed as a function $V=f(t)$, simulating drivetrain (clutch, transmission) operating characteristics, vehicle geometrical parameters, and driver behavior. Measurements of exhaust gas thermodynamic parameters (temperature, pressure, and mass flow) as well as the voltage and current generated by the thermoelectric modules were performed during tests of our own design. Based on the results obtained, the flow of exhaust gas energy in the entire exhaust system was determined along with the ATEG power output. The ideal area of the exhaust system for location of the ATEG was defined to ensure the highest thermal energy recovery efficiency.
\end{abstract}

Key words: Waste heat recovery, ATEG, dynamic test bed, engine efficiency

\section{INTRODUCTION}

Carmakers are obliged to reduce $\mathrm{CO}_{2}$ emissions and fuel consumption according to current legislation. ${ }^{1-4}$ At a conference organized by the German Institute of Automotive Engineering (IAV) in Iriyama in $2014,{ }^{5}$ the representative of Toyota Motor Corporation presented the company's strategy for reduction of fuel consumption to comply with increasingly stringent $\mathrm{CO}_{2}$ emission limits. The strategy is based on reducing heat loss from vehicles, primarily through use of automotive thermoelectric generators (ATEGs). ${ }^{5}$ A prototype thermoelectric generation system (TEGS) based on an ATEG was presented. Cleary et al. ${ }^{6}$ presented two prototype ATEGs aimed at passenger vehicle and heavy-duty vehicle (HDV) engines. In the first case, the presented ATEG had power rating of $200 \mathrm{~W}$, designed for a Honda Accord fit with a

(Received June 2, 2016; accepted January 1, 2017;

published online February 8, 2017) spark-ignition (SI) engine. The second generator was designed for a tracked combat vehicle (Bradley) used mainly by the US Army. In addition to the above solutions, other prototypes developed by international research and development centers have been presented in literature..$^{7-9}$

The determining factor in the development of ATEGs is the development of thermoelectric materials with higher $Z T$ values. Intense research is therefore being carried out to implement thermoelectric modules based on mass-producible materials that can generate more power ${ }^{10-14}$ and operate over a broader temperature range compared with conventional $\mathrm{Bi}_{2} \mathrm{Te}_{3}$-based solutions.

Based on this need to reduce fuel consumption and $\mathrm{CO}_{2}$ emissions from modern powertrains as well as the rapid technological advancement of exhaust gas energy recovery systems, we have developed an ATEG solution. Its main assumptions and the results of measurements performed on a SI engine were presented in Ref. 15. This study is a 
continuation of that research to demonstrate the increased efficiency of powertrains based on this solution. Analysis of the results of tests carried out on a compression-ignition (CI) engine is presented herein.

\section{RESEARCH METHODOLOGY}

Measurements of the recovery of waste energy from the exhaust gas using an ATEG were carried out on an engine dynamometer on a 1.3-l small diesel engine (SDE) fit with a diesel oxidation catalyst (DOC). The measurements were carried out using an actual vehicle driving cycle whose characteristics were presented in Ref. 16. Merkisz et al. ${ }^{16}$ also presented a detailed description of the engine dynamometer, the ISAC 400 simulation software, and the portable emission measurement system (PEMS) equipment used. This study was carried out on an ATEG of the authors' proprietary design.

The ATEG is a modular generator consisting of three main components: a heat exchanger, commercial thermoelectric modules, and cooling components (Fig. 1). The main part of the heat exchanger, on which an array of thermoelectric modules are fit, has rectangular shape. Its width is almost twice its height. To ensure a uniform temperature distribution along the heat exchanger, ribbing with increasing cross-section is mounted inside. It was calculated that four modules would be arranged longitudinally on each side of the heat exchanger. There were two rows of modules on the top and bottom of the heat exchanger, and one row on each side, giving a total of 24 modules. One dedicated cooling panel was attached to the heat exchanger via a screw connection for each row of modules to allow application of thermoelectric modules having different thickness. Special silicated thermal grease was applied between the modules and the walls of the heat exchanger to facilitate heat transfer from the walls of the heat exchanger to the hot side of the module and help reduce heat leaks caused by the

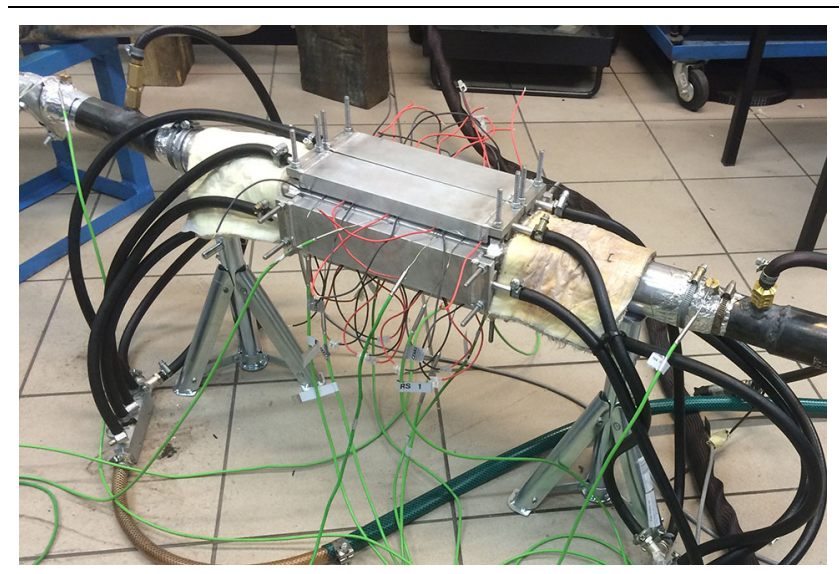

Fig. 1. ATEG. surface roughness of the heat exchanger as well as other material imperfections.

\section{ENERGY BALANCE OF THE 1.3-L SDE EXHAUST SYSTEM WITHOUT ATEG}

The temperature and pressure of the exhaust gas of the 1.3-1 SDE were measured (Fig. 2). The temperature of the exhaust gas was measured at three points: point $1\left(t_{1}\right.$, downstream of the diesel oxidation catalyst), point 2 ( $t_{2}$, upstream of the muffler $)$, and point $3\left(t_{3}\right.$, downstream of the muffler). The pressure was measured at two points, upstream $\left(p_{1}\right)$ and downstream $\left(p_{2}\right)$, to determine the power loss resulting from the pressure drop due to the flow resistance of the exhaust gas. The PEMS equipment was also used to measure the emissions and the thermodynamic parameters of the exhaust gas.

The dynamic test used a vehicle speed profile expressed as $V=f(t)$, as per the assumptions described previously by the authors ${ }^{1}$ (Fig. 3). In addition, the test recorded the engine torque curve, indicating negative values at many stages of the test. These values were obtained following reproduction of the engine braking on the engine dynamometer; in this case, the power was transmitted from the electric motor of the test stand to the engine crankshaft. In static dynamometers, torque is transferred from the engine to the dynamometer. The actual vehicle driving cycle used to simulate actual conditions generated maximum torque of $T=200 \mathrm{~N} \mathrm{~m}$. The average value of the torque, taking into account the negative values, was $T=22 \mathrm{~N} \mathrm{~m}$, while the maximum mass flow rate of the exhaust gas reached $56.8 \mathrm{~kg} / \mathrm{h}$ (Fig. 4).

To eliminate the influence of the engine warmup phase on the temperature distribution in the exhaust system, the measurements started from a steady thermal state (with engine coolant temperature of $90^{\circ} \mathrm{C}$ ). To this end, the warm-up phase, during which the power unit operated at constant engine speed and load, was defined in the ISCA 400 algorithm software prior to initiation of the test. After reaching the predetermined coolant temperature, exhaust conditioning took place, i.e., the engine was idled to stabilize the temperature of the exhaust gas. It is noteworthy that measurements were also performed during the cold start phase, showing that most of the thermal energy flow was utilized to reach the diesel oxidation catalyst "light-off" temperature. For CI engines, it takes much longer to reach the catalytic system operating temperature range compared with SI engines. The highest temperature of the exhaust gas at the measuring points of the driving cycle was (Fig. 5):
(a) $t_{1}=170.3^{\circ} \mathrm{C}$
(b) $t_{2}=123.6^{\circ} \mathrm{C}$
(c) $t_{3}=96.7^{\circ} \mathrm{C}$ 


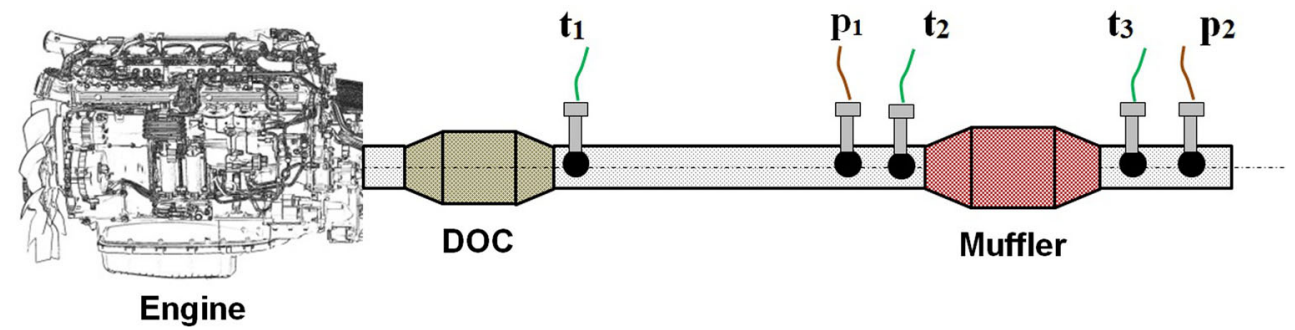

Fig. 2. Temperature and pressure measurement points in the 1.3-I SDE exhaust system.

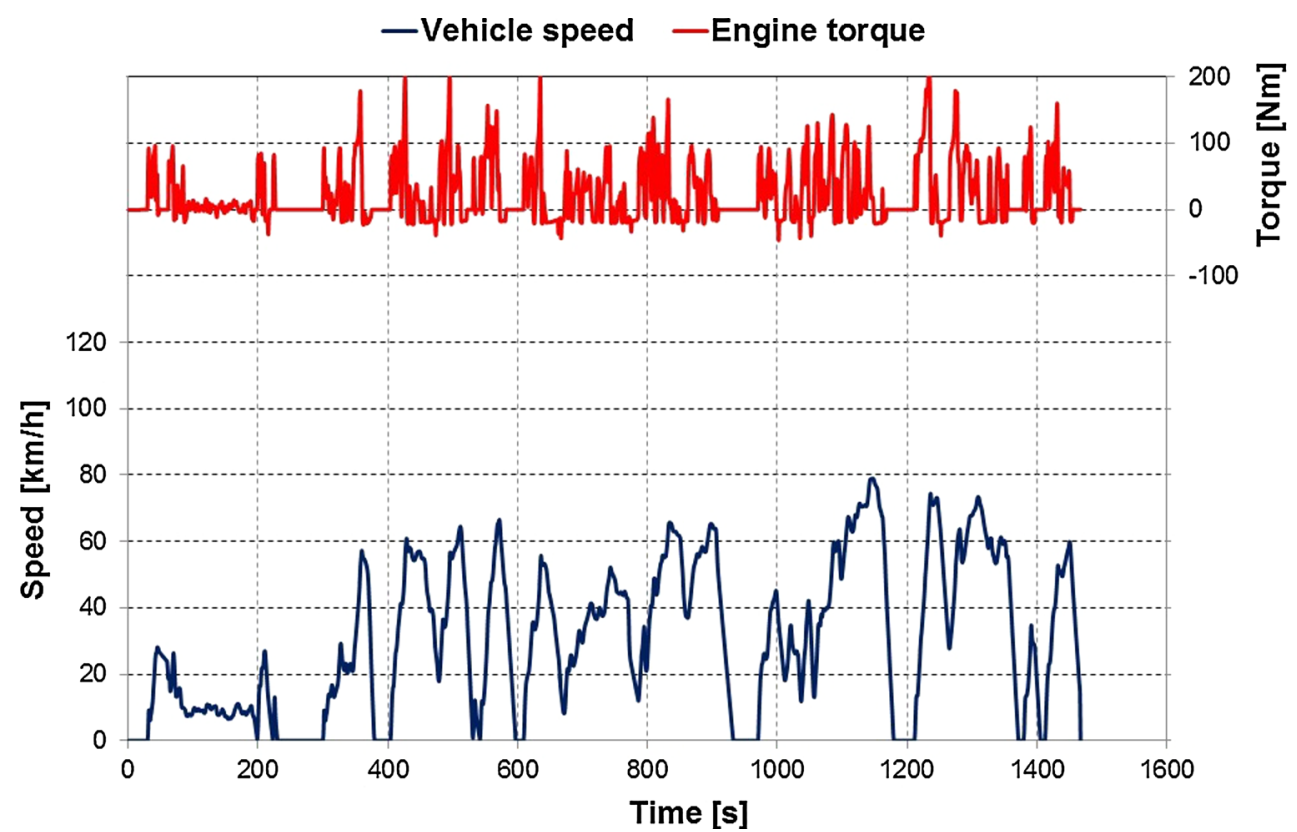

Fig. 3. Vehicle speed as function of time $V=f(t)$ and engine torque as $T=f(t)$ recorded during an actual vehicle driving cycle reproduced on a dynamic engine test bed.

The nature of the test also reflects the amount of energy flow supplied as fuel; its total value amounted to 22.1 MW (Fig. 6). This determined the amount of energy flow in the exhaust gas at the considered measuring points, with average values of:
(a) $Q_{\mathrm{Ex} 1}=3.9 \mathrm{~kW}$
(b) $Q_{\mathrm{EX} 2}=2.7 \mathrm{~kW}$
(c) $Q_{\mathrm{EX} 3}=1.9 \mathrm{~kW}$

Equation 1 was used to determine the power loss in the engine muffler caused by the pressure difference of the exhaust gas. The average power loss during the measurements was $p_{\text {loss }}=17.4 \mathrm{~W}$, and the maximum was $128.9 \mathrm{~W}$ (Fig. 7). Compared with the energy flow supplied in the form of fuel and the exhaust gas energy loss, this appears to be an insignificant share.

$$
p_{\text {loss }}=\Delta p \cdot \dot{V}_{\mathrm{EX}},
$$

where $p_{\text {loss }}$ is the power loss $(\mathrm{W}), \Delta p$ is the pressure drop $(\mathrm{Pa})$, and $\dot{V}_{\mathrm{EX}}$ is the volumetric flow rate of exhaust gas $\left(\mathrm{m}^{3} / \mathrm{s}\right)$.

\section{ENERGY BALANCE OF 1.3-L SDE EXHAUST SYSTEM FIT WITH ATEG}

Due to the low exhaust gas temperature obtained in the driving cycle, the ATEG was mounted directly downstream of the diesel oxidation catalyst (Fig. 8), ahead of the muffler. Five temperature sensors were placed in the exhaust system: downstream of the catalytic converter $\left(t_{1}\right.$, point 1$)$, and upstream and downstream of the ATEG ( $T_{\mathrm{IN}}$ and $\left.T_{\text {OUT }}\right)$ and muffler $\left(t_{2}\right.$ and $\left.t_{3}\right)$.

For the measurements performed on the dynamic engine test stand with the 1.3-l SDE, the temperature at point 1 , downstream of the diesel oxidation 


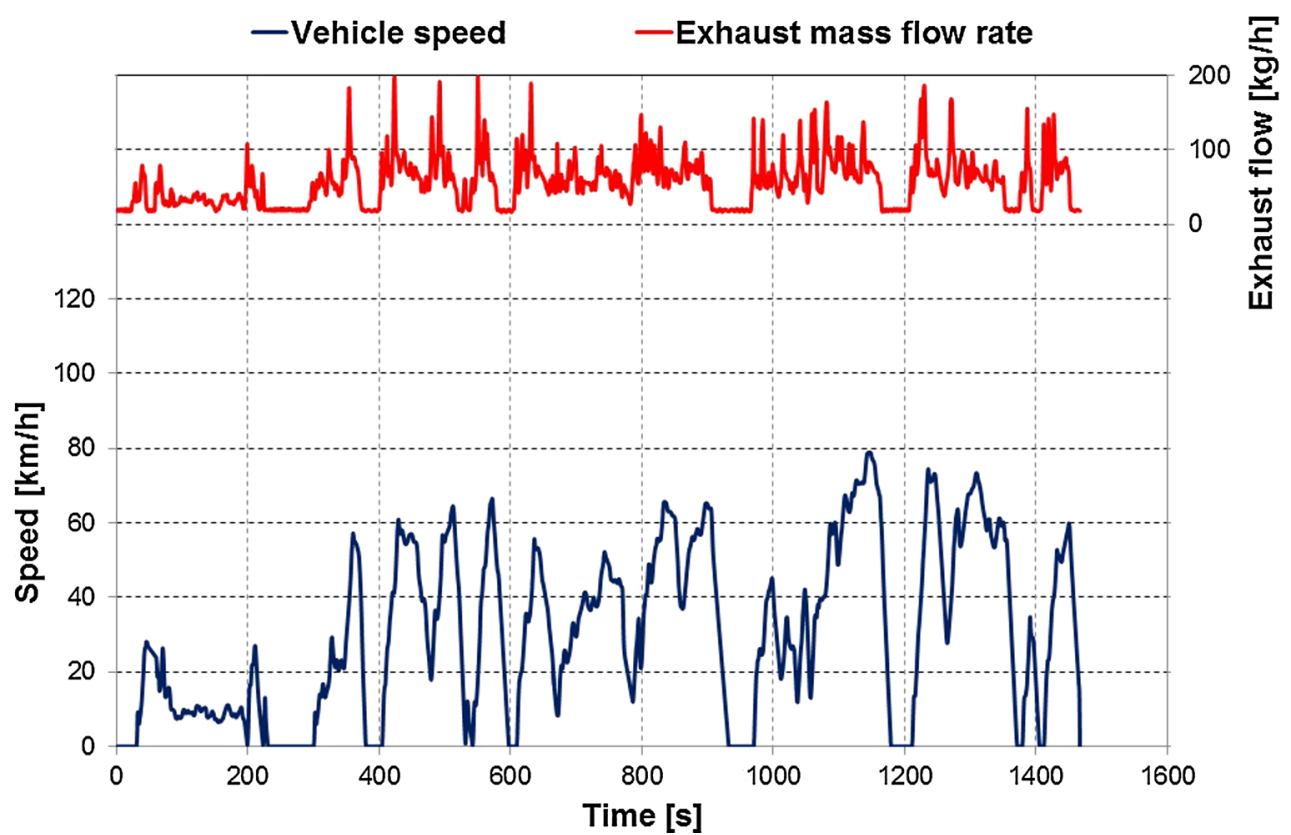

Fig. 4. Vehicle speed as function of time $V=f(t)$, along with the exhaust mass flow rare recorded during an actual vehicle driving cycle reproduced on a dynamic engine test bed.

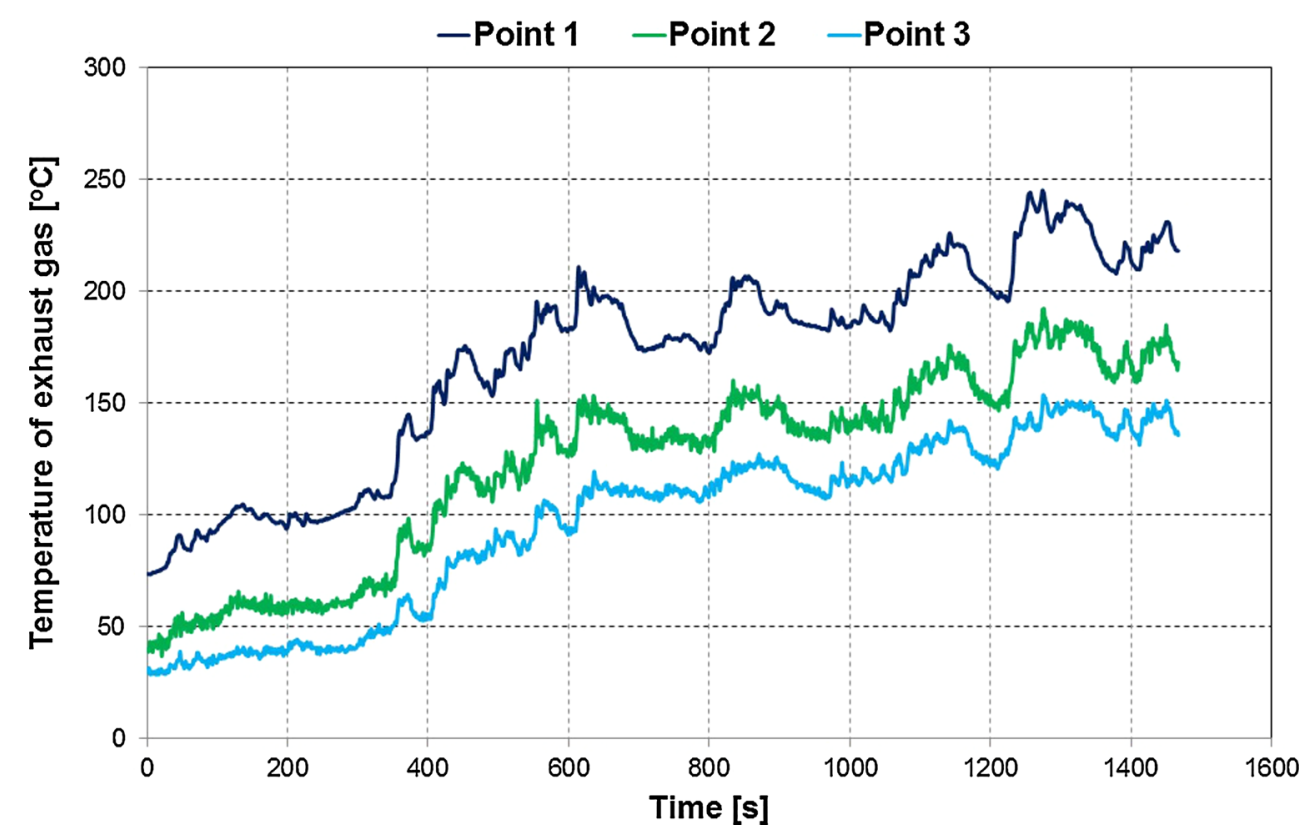

Fig. 5. Temperature distribution in exhaust system during an actual vehicle driving cycle reproduced on a dynamic engine test bed.

catalyst, did not exceed $250^{\circ} \mathrm{C}$ (Fig. 9). At the inlet to the ATEG, it reached a maximum of $200^{\circ} \mathrm{C}$. It was also observed that the measured temperature increased with time. This was related to the thermal stabilization of the exhaust system, reached after $400 \mathrm{~s}$ of operation. The maximum temperature drop in the ATEG and muffler was $53^{\circ} \mathrm{C}$ and $31^{\circ} \mathrm{C}$. The design of the engine dynamometer forced the ATEG location to be at $50 \mathrm{~cm}$ from the end of the diesel oxidation catalyst.

\section{TEMPERATURE DISTRIBUTION ON WALLS OF THERMOELECTRIC GENERATOR}

An important factor influencing the power obtained from the ATEG is the temperature distribution on its walls. Due to the operating nature of the TEM modules, the distribution must be uniform on each of them. The developed design uses 24 commercial TEM units, combined in series into a single system. In this configuration, the current flows through all the elements, maintaining a 


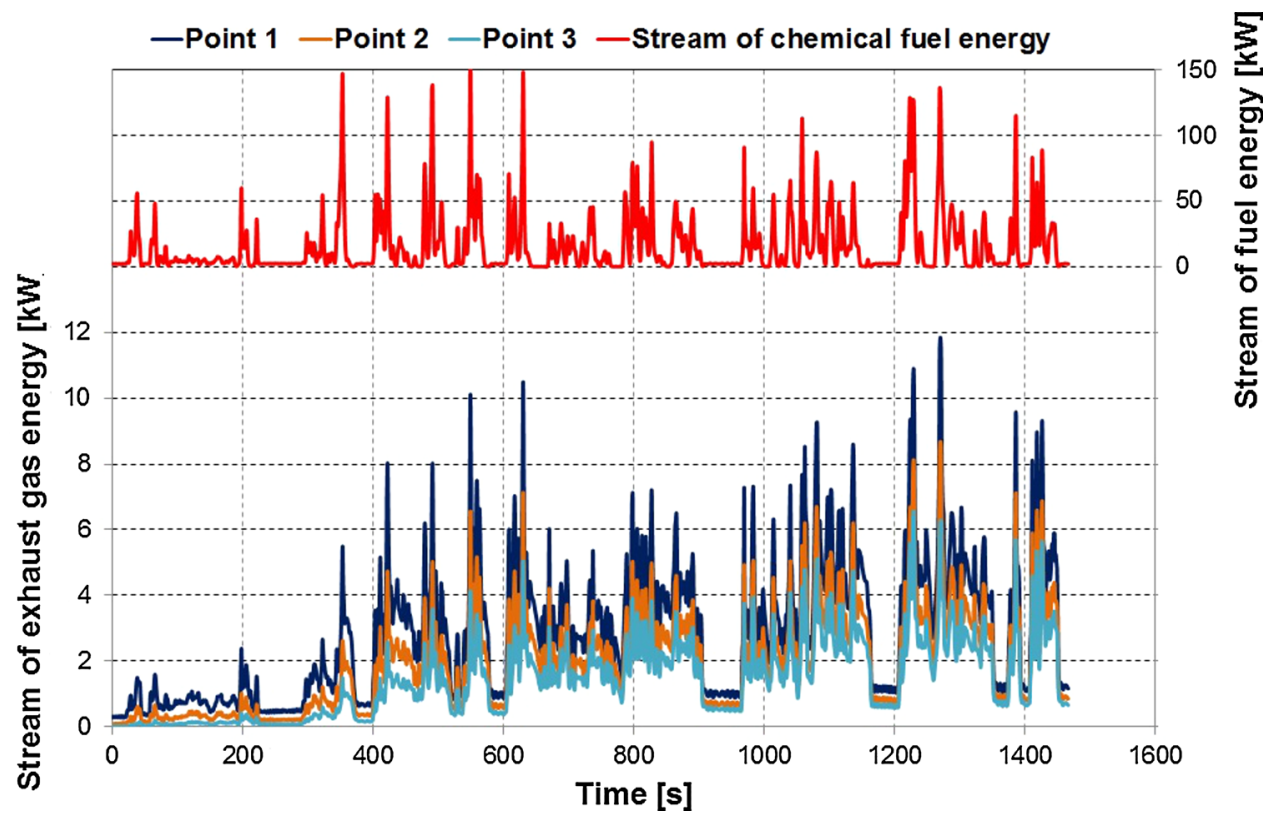

Fig. 6. Stream of exhaust gas energy with stream of chemical energy of fuel during an actual vehicle driving cycle reproduced on a dynamic engine test bed.

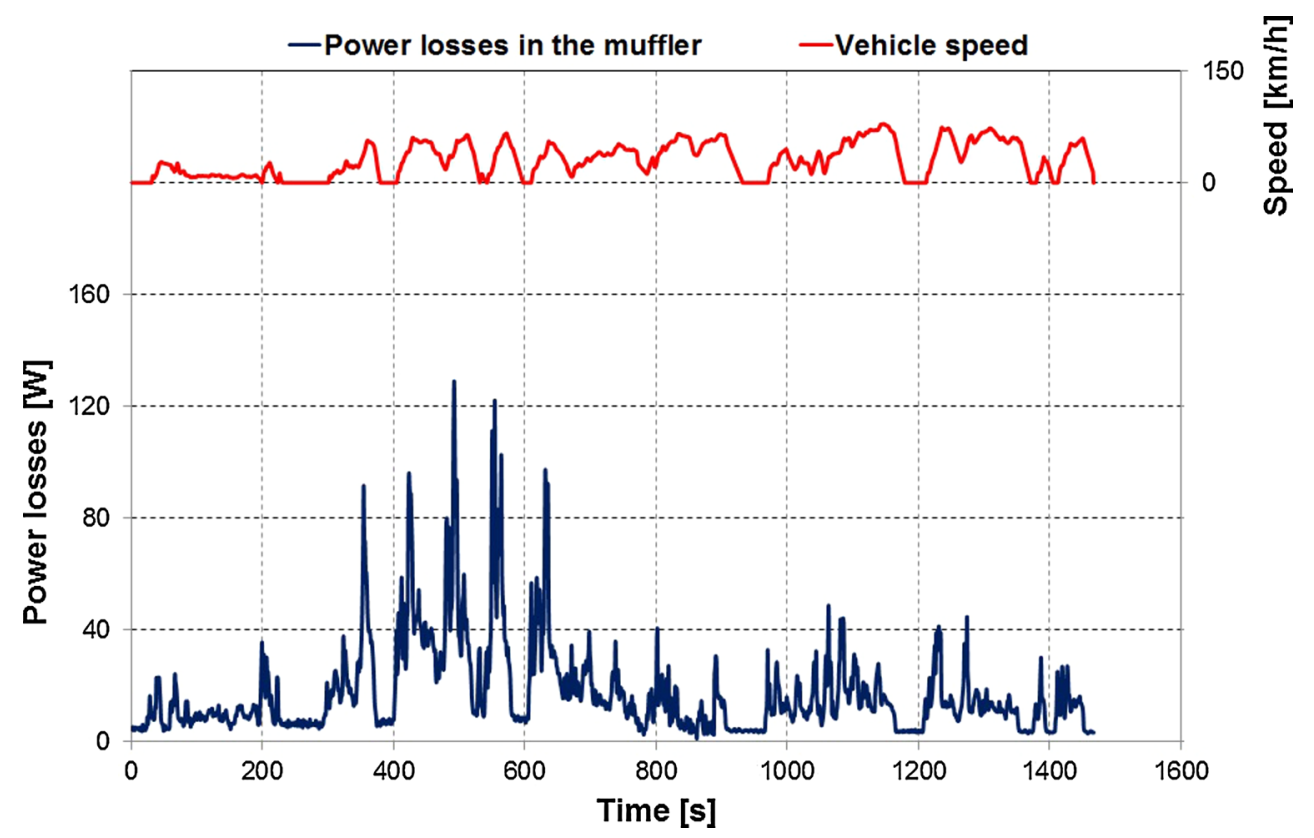

Fig. 7. Power loss in muffler of 1.3-I SDE according to measurements made on the dynamic engine test bed during an actual vehicle driving cycle.

constant value $I$, while the electrical voltage $U$ is additive. The operation of each TEM module is closely linked to the temperature difference between its hot and cold side. If temperature differences occur between individual TEM modules when connected in series, the total value of the voltage and the current that the system generates will change, which will translate into the power generated by the ATEG. Therefore, the temperature distribution on individual walls of the ATEG during the tests is presented. The generator consists of four walls that, for the purpose of this analysis, are denoted as top, bottom, left, and right. The top and bottom walls have two rows of four TEM modules, while the lateral (left and right) walls have one row each. One temperature sensor was placed on each hot side of the ATEG. The temperature measurement 


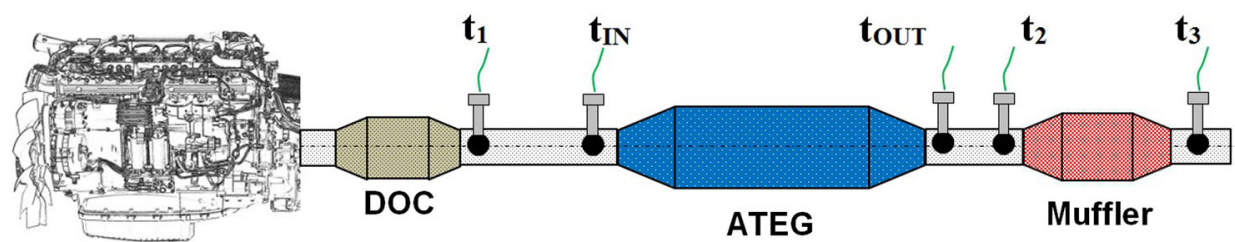

Engine

Fig. 8. Temperature measurement points in 1.3-I SDE exhaust system fit with the ATEG.
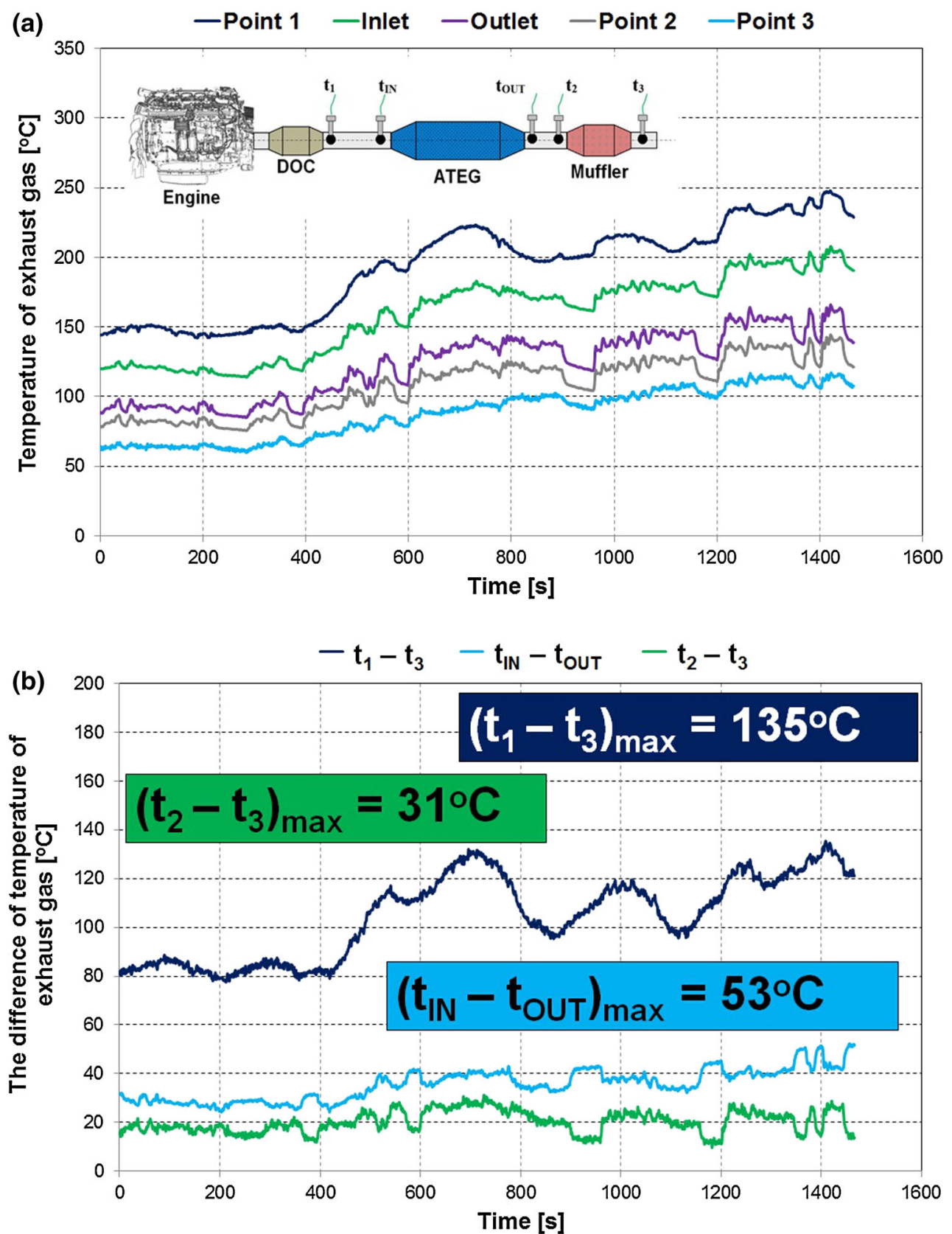

Fig. 9. Exhaust system temperature of 1.3-I SDE fit with an ATEG on a dynamic engine test bed during an actual vehicle driving cycle: (a) at points $t_{1}$ to $t_{3}, t_{\mathrm{IN}}$, and $t_{\mathrm{OUT}}$, (b) differences $t_{1}-t_{3}, t_{\mathrm{N}}-t_{\mathrm{OUT}}$, and $t_{2}-t_{3}$. 

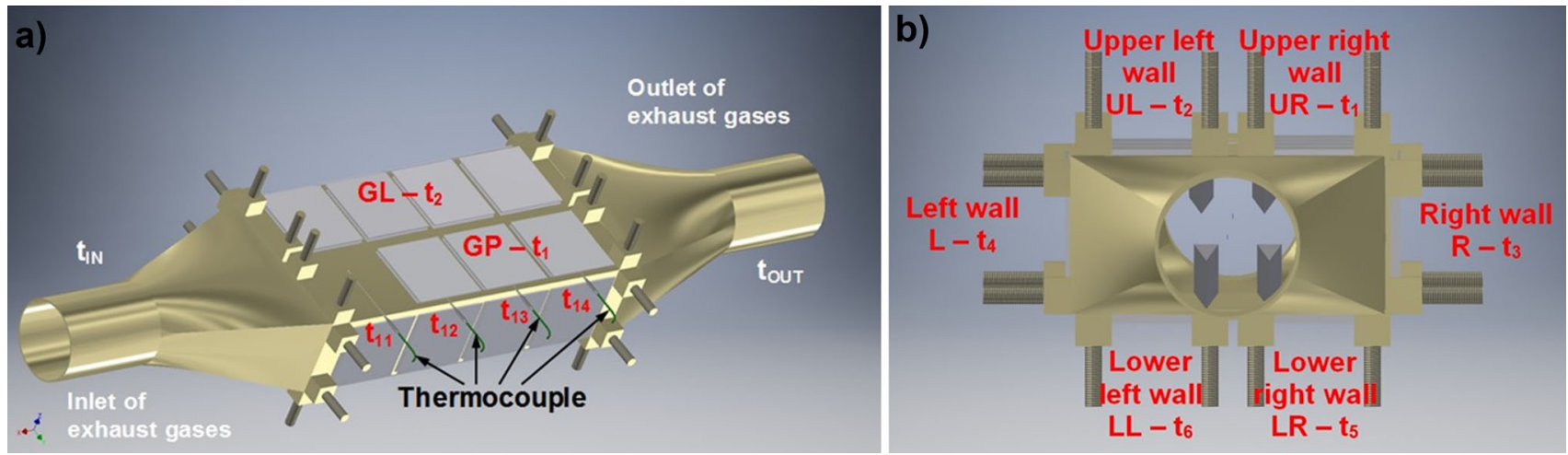

Fig. 10. Temperature measuring points on the ATEG walls: (a) ATEG, (b) ATEG walls.

points on the ATEG walls were defined in the following manner (Fig. 10):

(a) Upper right (UR) wall: $t_{11}, t_{12}, t_{13}, t_{14}$

(b) Upper left (UL) wall: $t_{21}, t_{22}, t_{23}, t_{24}$

(c) Right (R) wall: $t_{31}, t_{32}, t_{33}, t_{34}$

(d) Left (L) wall: $t_{41}, t_{42}, t_{43}, t_{44}$

(e) Lower right (LR) wall: $t_{51}, t_{52}, t_{53}, t_{54}$

(f) Lower left (LL) wall: $t_{61}, t_{62}, t_{63}, t_{64}$

As part of the development of the ATEG design, analysis based on computational fluid dynamics (CFD) tools was also conducted. These analyses used the thermodynamic parameters of the exhaust gas obtained from measurements carried out under actual operating conditions of a motor vehicle fit with a diesel engine. Based on the computer simulations, it was found that the walls of the ATEG received a uniform distribution of exhaust gas energy flow.

The temperature in the ATEG was measured at 26 points. Analysis of the results revealed that the temperature differences between modules were insignificant and showed a linear relationship, so only data for the first and last TEM units in a row are presented. The test driving cycle performed on a dynamic engine test bed with the 1.3-1 SDE resulted in similar temperature distributions on each wall. The study was carried out for a thermally stable engine (with coolant temperature of $90^{\circ} \mathrm{C}$ ). The engine was warmed up before each measurement and left for the temperature of the exchanger walls to stabilize. The temperature difference between the first and last TE module on each panel was calculated to obtain the mean value obtained throughout the test cycle:
(a) $\Delta t_{1}=t_{11}-t_{14}$
(b) $\Delta t_{2}=t_{21}-t_{24}$
(c) $\Delta t_{3}=t_{31}-t_{34}$
(d) $\Delta t_{4}=t_{41}-t_{44}$
(e) $\Delta t_{5}=t_{51}-t_{54}$
(f) $\Delta t_{6}=t_{61}-t_{64}$

On the top and bottom walls of the heat exchanger, the greatest temperature drops recorded were $4.93^{\circ} \mathrm{C}$ for $\Delta t_{1}$ and $4.89^{\circ} \mathrm{C}$ for $\Delta t_{2}$ (Fig. 11a). The differences on the side walls were slightly lower: $4.48^{\circ} \mathrm{C}$ for $\Delta t_{3}$ and $4.62^{\circ} \mathrm{C}$ for $\Delta t_{4}$ (Fig. 11b). The temperature distributions recorded on the walls of the heat exchanger resulted in the obtained values of voltage and current generated by the TEM modules in a given row. The temperatures of the upper and lower walls versus the side walls resulted in a greater difference than the changes recorded between the end modules in each row.

\section{WASTE ENERGY RECOVERY EFFICIENCY: ATEG EFFICIENCY}

Commercial $\mathrm{Bi}_{2} \mathrm{Te}_{3}$-based TEM units have energy conversion efficiency not exceeding $3 \%$. For the purpose of this research, commercial TMG-241-1.41.2 modules made by Ferrotec NORD with power of $9.4 \mathrm{~W}$ each were used, for a total of $225.6 \mathrm{~W}$. To determine the ATEG exhaust gas energy recovery potential, the waste energy recovery efficiency (tantamount to the ATEG efficiency) was defined, expressed as the ratio of the power generated by the TEM modules to the amount of energy present in the exhaust gas heat exchanger fit with the ATEG:

$$
\eta_{\mathrm{ATEG}}=\frac{P_{\mathrm{ATEG}}}{Q_{\mathrm{EX}}}=\frac{P_{\mathrm{ATEG}}}{\dot{m}_{\mathrm{EX}} \cdot c_{\mathrm{p}} \cdot\left(t_{\mathrm{EX}}-t_{\mathrm{A}}\right)},
$$

where $\eta_{\text {ATEG }}$ is the ATEG efficiency (-), $P_{\text {ATEG }}$ is the power generated by the TEM modules $(\mathrm{kW}), Q_{\mathrm{Ex}}$ is the energy in the exhaust gas $(\mathrm{kW}), \dot{m}_{\mathrm{EX}}$ is the exhaust mass flow rate $(\mathrm{kg} / \mathrm{s}), t_{\mathrm{Ex}}$ is the temperature of the exhaust gas $\left({ }^{\circ} \mathrm{C}\right)$, and $t_{\mathrm{A}}$ is the temperature of ambient air $\left({ }^{\circ} \mathrm{C}\right)$.

The power of the TEM module was determined based on the voltage and current recorded by the developed measurement system. The amount of energy in the exhaust gas was calculated using Eq. 2. The exhaust gas temperature $t_{\mathrm{Ex}}$ was taken as the average ATEG temperature: 

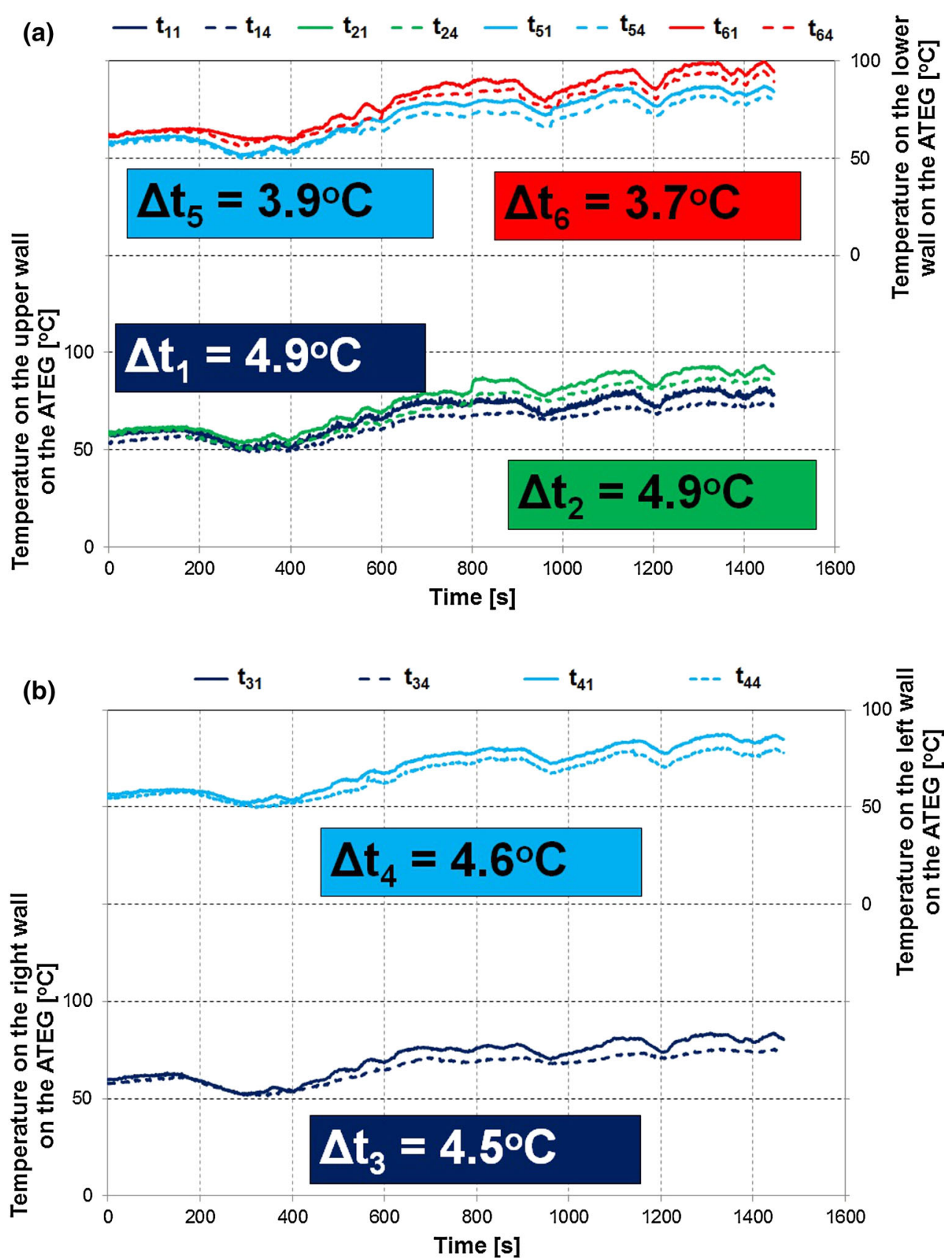

Fig. 11. Temperature distribution in the ATEG mounted in the exhaust system of the 1.3 SDE during an actual vehicle driving cycle: (a) upper and lower walls, (b) side walls.

$$
\Delta t_{\mathrm{ATEG}}=\frac{t_{\mathrm{IN}}-t_{\mathrm{OUT}}}{2}
$$

where $\Delta t_{\mathrm{ATEG}}$ is the average temperature inside the ATEG $\left({ }^{\circ} \mathrm{C}\right), t_{\mathrm{IN}}$ is the temperature at the inlet to the ATEG $\left({ }^{\circ} \mathrm{C}\right)$, and $t_{\text {OUT }}$ is the temperature at the outlet from the ATEG $\left({ }^{\circ} \mathrm{C}\right)$.

In the measurements carried out on the 1.3-1 SDE on the dynamic test stand, relatively low values of power were generated by the ATEG. Therefore, only the waste heat recovery efficiency for module coolant temperature of $t_{\text {cooling }}=10^{\circ} \mathrm{C}$ is presented (Fig. 12), although other measurements for $t_{\text {cooling }}=50^{\circ} \mathrm{C}$ and $90^{\circ} \mathrm{C}$ were performed as well. The highest value occurred during deceleration (simulated vehicle braking) and zero acceleration (vehicle stationary). This was mainly due to the advantage of a constant exhaust gas mass flow resulting in a uniform temperature distribution on the walls of the heat exchanger and the ATEG. This reduced the pressure pulsations in the engine exhaust system. With increasing speed (vehicle 


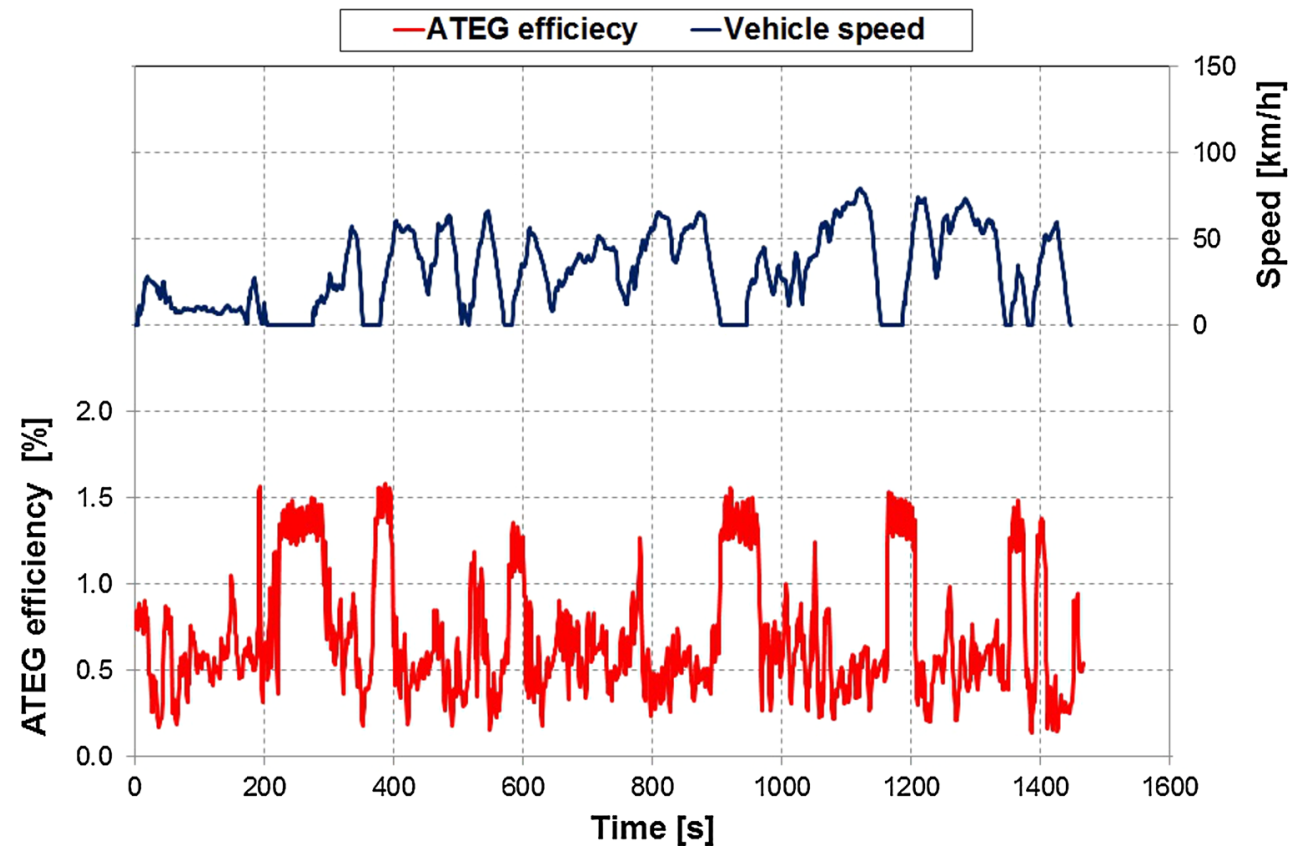

Fig. 12. Efficiency of ATEG fit to the exhaust system of a 1.3-I SDE during an actual vehicle driving cycle.

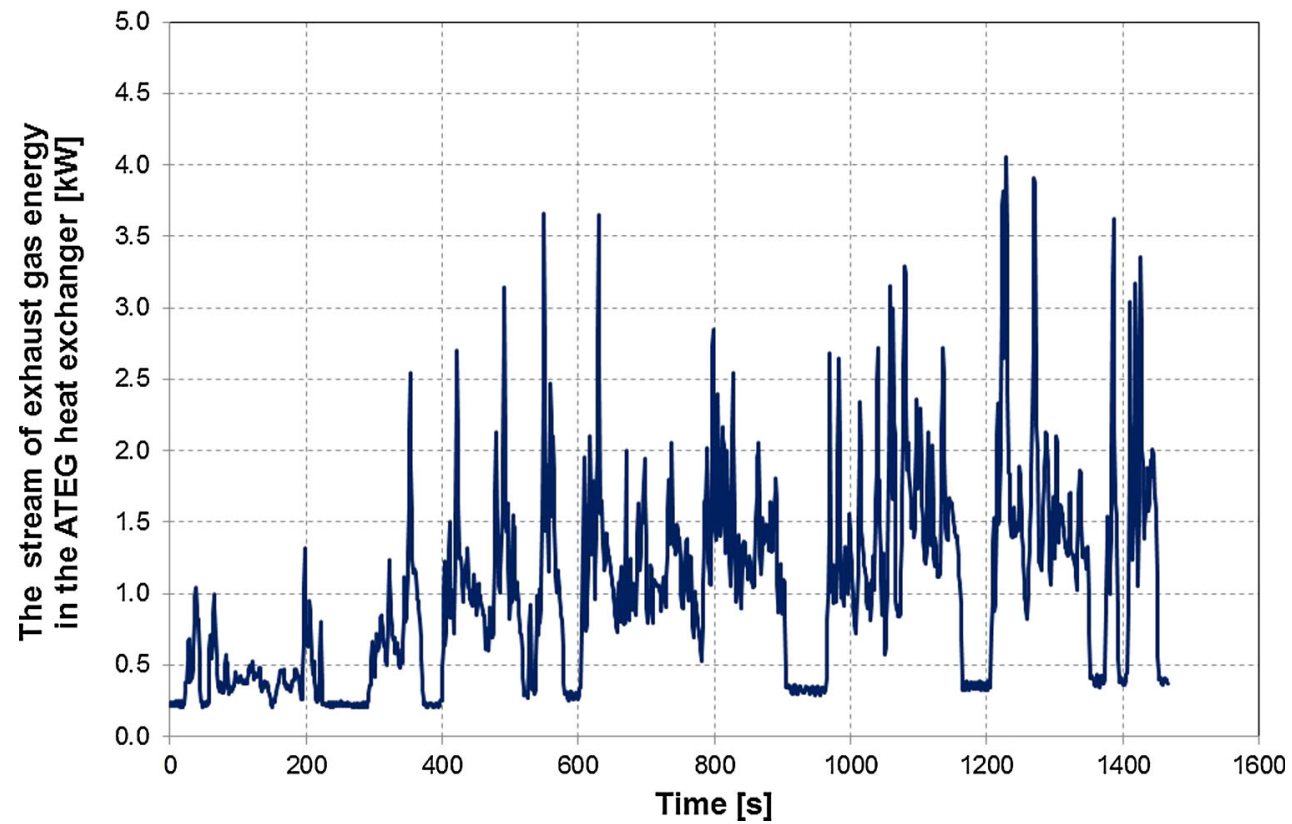

Fig. 13. Exhaust gas energy flow in the ATEG heat exchanger mounted in the exhaust system of a 1.3-I SDE during an actual vehicle driving cycle.

acceleration), there was a cyclical decline in the waste energy recovery efficiency due to sudden changes in the exhaust gas thermodynamic parameters. The key, in this case, was the relatively low temperature of the exhaust gas; the value on the walls of the heat exchanger did not exceed $100^{\circ} \mathrm{C}$ in the tests.

In addition to determining the ATEG efficiency, it is also important to determine the potential exhaust gas energy recovery (waste energy) that is transferred to the heat exchanger walls. In this case, the temperature drop $\Delta t_{\text {ATEG }}$ plays a key role. Some of the designated waste energy is lost on the walls of the diffuser and the confusor of the heat exchanger as well as due to internal flow resistance. For this analysis, it was assumed that this equaled half of the total ATEG calculated exhaust gas energy flow. This value was obtained based on literature data. In 


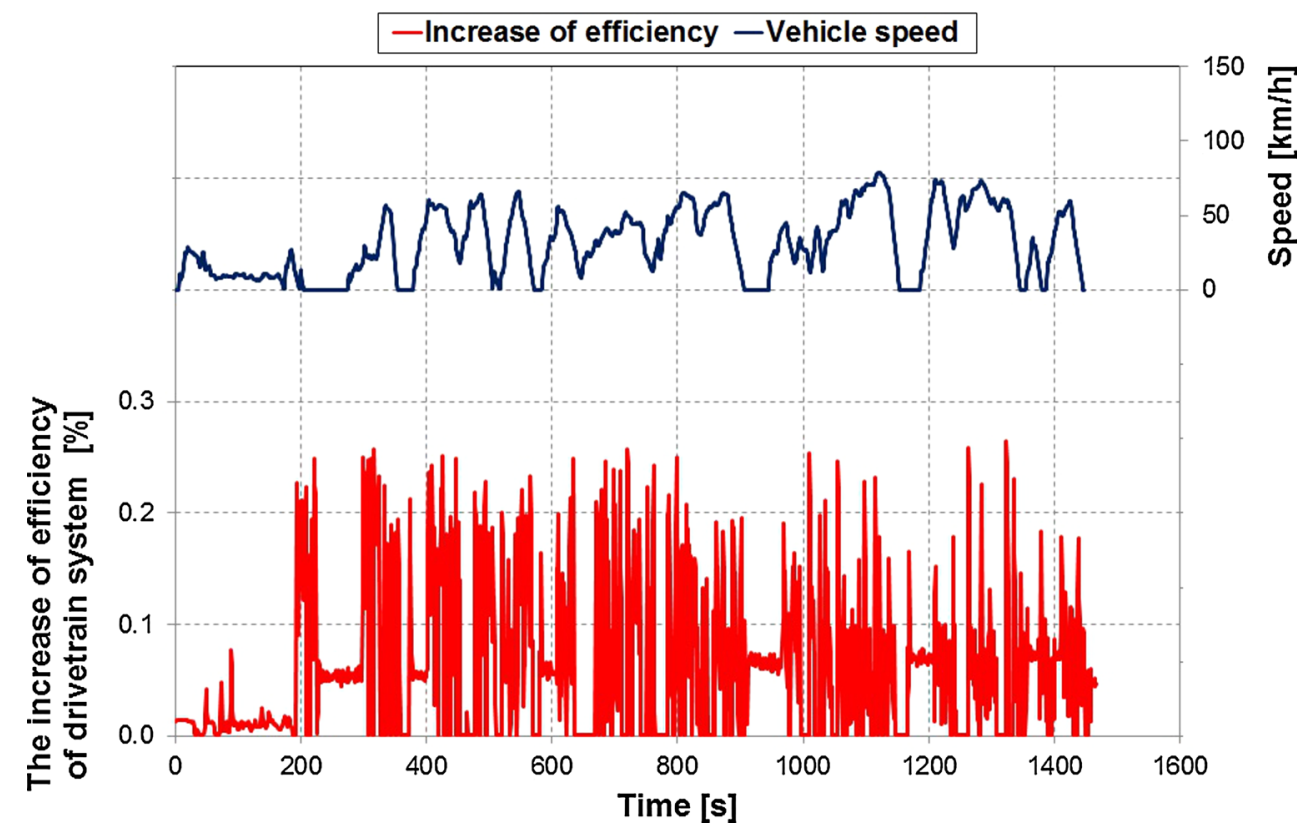

Fig. 14. Increase in efficiency of powertrain fit with 1.3-I SDE including the ATEG during an actual vehicle driving cycle.

the test driving cycle, the average value of the exhaust gas energy flow in the ATEG was $Q_{\mathrm{Ex}}=0.67 \mathrm{~kW}$, reaching a maximum of $4.05 \mathrm{~kW}$ (Fig. 13).

\section{POWERTRAIN EFFICIENCY OF 1.3-L SDE INCLUDING THE ATEG}

The overall efficiency of an internal combustion engine is a measure of the use of the energy contained in the fuel. This provides a view of the conversion efficiency of the heat energy contained in the fuel into mechanical energy of the engine. This efficiency is also considered the inverse of the specific fuel consumption and can be expressed as

$$
\eta_{\mathrm{o}}=\frac{P_{\mathrm{e}}}{G \cdot \mathrm{GCV}}=\frac{1}{\mathrm{BSFC} \cdot \mathrm{GCV}}
$$

where $\eta_{\mathrm{o}}$ is the overall engine efficiency, $P_{\mathrm{e}}$ is the engine power output, $G$ is the fuel consumption per second, GCV is the gross calorific value, and BSFC is the brake specific fuel consumption.

To determine the efficiency of a powertrain $\eta_{\mathrm{DSE}}$ fit with an ATEG, formula (4) should be used, considering the power generated by the generator $P_{\text {ATEG }}$. Adding the ATEG power $P_{\text {ATEG }}$ to the output of the engine $P_{\mathrm{e}}$ is justified, because the generator produces electrical power from the exhaust gas energy, which, in internal combustion engines, is treated as a loss (failure to use this waste energy generated by combustion of the air-fuel mixture). This increases the efficiency of the powertrain system, because the engine produces a greater amount of energy from the same amount of fuel. The thermal energy loss of the exhaust gas is also limited. To determine the increase of the powertrain efficiency through the application of an ATEG in the exhaust system, the overall efficiency of the engine $\eta_{\mathrm{o}}$ must be subtracted from the efficiency of the powertrain $\eta_{\mathrm{DSE}}$ :

$$
\begin{aligned}
\Delta \eta_{\mathrm{DSE}} & =\eta_{\mathrm{DSE}}-\eta_{\mathrm{o}}=\frac{\left|P_{\mathrm{e}}+P_{\mathrm{ATEG}}\right|}{G \cdot \mathrm{GCV}}-\frac{P_{\mathrm{e}}}{G \cdot \mathrm{GCV}} \\
& =\frac{P_{\mathrm{ATEG}}}{G \cdot \mathrm{GCV}}=\frac{(U \cdot I)_{\mathrm{ATEG}}}{G \cdot \mathrm{GCV}},
\end{aligned}
$$

where $\eta_{\mathrm{DSE}}$ is the efficiency of the powertrain including the ATEG, $U_{\mathrm{ATEG}}$ is the voltage generated by the TEM modules, and $I_{\mathrm{ATEG}}$ is the current generated by the TEM modules.

The increase in the efficiency of the powertrain fit with the 1.3-l SDE due to the power generated by the ATEG did not exceed $0.27 \%$ (Fig. 14), and the average value throughout the experiment was $0.06 \%$. This is mainly due to the low exhaust gas temperature, which was a consequence of the low energy consumption in the test driving cycle. The greatest increase in powertrain efficiency was recorded at maximum torque, reflecting the higher exhaust gas temperature. These, however, were only single points recorded in the measurements during high acceleration.

\section{CONCLUSIONS}

Analysis of the exhaust gas energy flow for a 1.3-1 SDE during an actual driving test cycle for a vehicle on a dynamic engine test bed showed that the power generated by the ATEG contributed only a slight increase to the powertrain efficiency. This is due to several factors. Most important is the low temperature of the exhaust gas in the engine exhaust 
system, which directly determines the temperature distribution on the walls of the ATEG heat exchanger, which did not exceed $100^{\circ} \mathrm{C}$ throughout the test. Therefore, a change of the ATEG location is expected in further research. The preferred area of the exhaust system for installation of the energy recovery system is the section to the right, downstream of the exhaust aftertreatment systems. This will increase the temperature both at the inlet to the generator and on the walls.

The developed ATEG design is characterized by a nearly uniform temperature distribution on each row of TEM modules. The greatest temperature differences between the first and last module did not exceed $5^{\circ} \mathrm{C}$. The temperature differences among the walls were slightly higher. Such a distribution of temperatures results in similar values of voltage and current generated by the TEM modules. This study also determined the exhaust gas energy recovery potential of the ATEG heat exchanger. The average value of waste energy, taking into account the loss, was $0.67 \mathrm{~kW}$ with a maximum of $4.05 \mathrm{~kW}$. The efficiency of the ATEG varied in the range from $0.14 \%$ to $1.6 \%$. In further work aimed at improving the efficiency of the ATEG, a change in the ribs of the internal heat exchanger is planned to improve the transfer of the energy flow from the exhaust gas to the generator walls. Specific changes in the design will be presented in subsequent publications.

\section{ACKNOWLEDGEMENT}

Funding was provided by Narodowe Centrum Badań i Rozwoju (Grant No. PBS3/A6/25/2015).

\section{OPEN ACCESS}

This article is distributed under the terms of the Creative Commons Attribution 4.0 International License (http://creativecommons.org/licenses/by/4.0/), which permits unrestricted use, distribution, and reproduction in any medium, provided you give appropriate credit to the original author(s) and the source, provide a link to the Creative Commons license, and indicate if changes were made.

\section{REFERENCES}

1. M. Bajerlein and L. Rymaniak, Appl. Mech. Mater. 518, 96 (2014). doi:10.4028/www.scientific.net/AMM.518.96.

2. A. Elalem and M.S. EL-Bourawi, Int. J. Mater. Form. 3, 663 (2010). doi:10.1007/s12289-010-0857-2.

3. S. Glover, R. Douglas, L. Glover, G. McCullough, and S. McKenna, Int. J. Automot. Technol. 16, 399 (2015). doi: 10.1007/s12239-015-0041-2.

4. M. Weißner, M. Schüttenhelm, T. Menzel, S. Watzl, K. Wrede, and M. Frambourg, in 23rd Aachen Colloquium Automobile and Engine Technology 2014, Aachen 2014.

5. Y. Iriyama, in 4th Thermoelectric Conference Utilizing Waste Heat in Transport and Industry 2014, Berlin 2014.

6. M. Cleary, Y. Zhang, A. Mazzotta, H. Young, L. Meda, X. Wang, G. Joshi, J. Yang, M. Engber, and Y. Ma, in 4th Thermoelectric Conference Utilizing Waste Heat in Transport and Industry 2014, Berlin 2014

7. N. Esponisa, M. Lazard, L. Aixala, and H. Scherrer, J. Electron. Mater. 39, 1447 (2010). doi:10.1007/s11664010-1305-2.

8. S. Kim, S. Park, S. Kim, and S.-H. Rhi, J. Electron. Mater. 40, 811 (2011). doi:10.1007/s11664-011-1580-6.

9. R. Kühn, O. Koeppen, and J. Kitte, J. Electron. Mater. 43, 1521 (2014). doi:10.1007/s11664-013-2769-7.

10. R. Amatya and R.J. Ram, J. Electron. Mater. 41, 1011 (2012). doi:10.1007/s11664-011-1839-y.

11. P. Gao, I. Berkun, R.D. Matthew, F. Luzenski, X. Lu, P. Bordon Sarac, E.D. Case, and P. Hogan, J. Electron. Mater. 46, 1790 (2014). doi:10.1007/s11664-013-2865-8.

12. Ch. Han, Z. Li, and S. Dou, Chin. Sci. Bull. 59, 2073 (2014). doi:10.1007/s11434-014-0237-2.

13. J.Y. Jang and Y. Ch Tsai, Appl. Therm. Eng. 51, 677 (2013). doi:10.1016/j.applthermaleng.2012.10.024.

14. D. Vasilevskiy, J.-M. Simard, T. Caillat, R.A. Masut, and S. Turenne, J. Electron. Mater. 45, 1540 (2016). doi: 10.1007/s11664-015-4101-1.

15. J. Merkisz, P. Fuc, P. Lijewski, A. Ziolkowski, M. Galant, and M. Siedlecki, J. Electron. Mater. 45, 4028 (2016). doi:10.1007/s11664-016-4543-0.

16. J. Merkisz, P. Fuc, P. Lijewski, A. Ziolkowski, and K.T. Wojciechowski, J. Electron. Mater. 44, 1704 (2015). doi: 10.1007/s11664-014-3522-6. 